\title{
The infectivity and behaviour of exsheathed and ensheathed Heterorhabditis megidis infective juveniles
}

\author{
Catherine M. DEMPSEY * and Christine T. GRIFFIN \\ Institute of Bioengineering and Agroecology, and Department of Biology, National University of Ireland, \\ Maynooth, Co. Kildare, Ireland
}

Received: 20 January 2002; revised: 16 September 2002 Accepted for publication: 2 October 2002

\begin{abstract}
Summary - The consequences of sheath loss on infectivity and behaviour of infective juveniles (IJ) were investigated in Heterorhabditis megidis. Ensheathed IJ were more infective, killing 32\% of wax moth larvae, compared to $18 \%$ killed by exsheathed IJ. The percentage of time engaged in seven behavioural activities was recorded for individually stored IJ but no differences were found between exsheathed and ensheathed IJ. Immobility was the most common behavioural category exhibited by both exsheathed and ensheathed IJ, occupying one third of the observation time. Storage conditions affected the rate of exsheathment; $40 \%$ of IJ stored for 28 days in water in bulk (50 in $8 \mathrm{ml}$ ) exsheathed compared to only $23 \%$ of those stored individually (1 in $2 \mathrm{ml}$ ).
\end{abstract}

Keywords - activity, entomopathogenic nematodes, Heterorhabditidae, sheath.

Many nematode infective juveniles (IJ) retain the cuticle from the previous moult as a sheath. Loss of the sheath, or exsheathment, usually marks the transition to the parasitic phase of the life cycle (Rogers \& Somerville, 1957). In trichostrongyles, such as Haemonchus contortus, sheath loss occurs after ingestion by the host and before penetration of the host gut (Patel \& Campbell, 1997), while the sheath of the hookworm Ancylostoma tubaeforme is discarded during penetration of host epidermis (Matthews, 1972). Insect-parasitic nematodes, Heterorhabditis spp., also lose their sheath while attempting penetration of an insect host and prior to entry into the host haemocoel (Bedding \& Molyneux, 1982). Infective juveniles of parasites including heterorhabditids can also lose their sheath during storage in water (Matthews, 1972; Campbell \& Gaugler, 1991a, 1992; Jung, 1991).

In heterorhabditids, the sheath has been shown to protect against desiccation (Womersley, 1990; Campbell \& Gaugler, 1991b; O'Leary et al., 1998), freezing (Wharton \& Surrey, 1994) and nematophagous fungi (Kaya, 1990; Timper \& Kaya, 1992). Exsheathment may also play a role in evasion of the host immune system (Peters \& Ehler, 1997). However, the sheath may also confer disadvantages, either by physically restricting movement or by decreasing the sensitivity of sensory receptors covered by it (Campbell \& Gaugler, 1992).

\footnotetext{
* Corresponding author, e-mail: catherinedempsey@ hotmail.com
}

The sheath is tightly fitted in the Heterorhabditidae, making it difficult to distinguish between ensheathed and exsheathed IJ. Methods used for obtaining sheathless insect-parasitic nematodes include chemical desheathment using sodium hypochlorite (Timper \& Kaya, 1989; Campbell \& Gaugler, 1991a, b, 1992; Ishibashi \& Takii, 1993) and movement through a barrier (Campbell \& Gaugler, 1991a). Both of these methods may influence the outcome of any behavioural tests performed with the sheathless IJ. Chemical desheathment is harsh and physically removes the sheath (Ishibashi \& Takii, 1993). The barrier method may select more active individuals (Campbell \& Gaugler, 1991a) affecting interpretation of behavioural observations. These methods have been used in studies of the effect of sheath loss in infectivity and mobility of only two species of entomopathogenic nematode, $\mathrm{H}$. bacteriophora and Steinernema carpocapsae (Campbell \& Gaugler, 1992). Exsheathed (as opposed to chemically desheathed) IJ of $H$. bacteriophora and S. carpocapsae did not differ in pathogenicity from ensheathed IJ (Campbell \& Gaugler, 1992). Mobility was unaffected by sheath loss in H. bacteriophorabut was increased in S. carpocapsae (Campbell \& Gaugler, 1992).

We have documented changes in the behaviour of $H$. megidis IJ during storage in water, including an increase in infectivity during the 2 nd or 3 rd week after 
emergence from the host cadaver (Griffin, 1996; Dempsey \& Griffin, 2002). Some IJ exsheath during the 1st week and others over several weeks: age related differences in behaviour may reflect an increase in the proportion of exsheathed IJ in the population. However, the effect of exsheathment on infectivity and behaviour of $H$. megidis IJ has not previously been studied. Here we introduce a method of obtaining pure batches of naturally exsheathed IJ and use them to investigate the behaviourand infectivity of ensheathed and exsheathed $H$. megidis IJ.

\section{Materials and methods}

\section{SOURCE AND MAINTENANCE OF NEMATODES}

Heterorhabditis megidis isolate UK211 was cultured in last instar larvae of the greater wax moth, Galleria mellonella, at $20^{\circ} \mathrm{C}$ according to the protocol of Woodring and Kaya (1988). Infective juveniles began to emerge about 14 days after infection. To obtain a batch of uniform age, IJ emerging prior to day 21 were harvested and discarded while those emerging over the following $24 \mathrm{~h}$ were harvested, washed three times by sedimentation in tap water and used immediately (on the day of harvest, day 0 ).

\section{EXSHEATHMENT, BEHAVIOUR AND INFECTIVITY OF INDIVIDUALLY STORED NEMATODES}

Infective juveniles were transferred individually to wells of a 24 well cloning plate $(92 \times 136 \mathrm{~mm}$, Sterilin, Stone, Staffs, UK) on day 0. Each well $(10 \times 10 \mathrm{~mm})$ contained $2 \mathrm{ml}$ of tap water and a single IJ was placed in one of the $16 \mathrm{~mm}^{2}$ sub-wells. The water in each well was replenished weekly and plates incubated at $20^{\circ} \mathrm{C}$ in the dark. This experiment was repeated a second time, each time with 25 replicate plates, each containing 24 IJ.

Exsheathment was assessed, by the presence of a cast sheath in the well, every 1-3 days over 4 weeks, at $\times 6$ magnification. Behaviour was described every 2-5 days between days 14 and 28. At each assessment, the behaviours of ten to 25 ensheathed and four to ten exsheathed, randomly chosen IJ were examined. Nematodes were filmed and the behaviour of each individual described during $1 \mathrm{~min}$. Seven behavioural categories were used (Dempsey \& Griffin, 2002): immobility, waving, body movement, coiling, head lifting, reverse wave and head thrusting. For each individual IJ, the frequency and duration of behaviour were catalogued using an original computer programme ('worm timer'), in which the start and end of each behavioural bout were registered by keystrokes. Time spent in each behavioural category was recorded during continuous observation, each behaviour being deemed to be exclusive of all others.

\section{INDIVIDUAL INFECTIVITY ASSAY}

This tested the ability of single IJ to parasitise an insect host. Ensheathed and exsheathed IJ were obtained from wells where they had been individually stored as described above. This experiment was conducted four times. In three experiments, the IJ were 15 days old but in the fourth they were 14-28 days old. In total, 251 exsheathed and 299 ensheathed IJ were tested. A $1.5 \mathrm{ml}$ Eppendorf tube was lined with a circle $(1.5 \mathrm{~cm}$ diam.) of filter paper, moistened with $40 \mu 1$ of tapwater. A single IJ was pipetted onto the paper and a G. mellonella larva put into the tube, which was then closed. After $24 \mathrm{~h}$, the G. mellonella larvae were washed in tapwater to remove adhering IJ. The number of insect larvae parasitised was recorded as the number of cadavers developing the characteristic red coloration over the following week.

\section{RATE OF EXSHEATHMENT IN BULK STORED NEMATODES}

Infective juveniles (50 in $8 \mathrm{ml}$ of tapwater) were incubated in a $5.5 \mathrm{~cm}$ diam. Petri dish at $20^{\circ} \mathrm{C}$ in the dark for 28 days from day 0. At 1-3 day intervals, sheaths present in each dish were counted, then removed from the dish using a Pasteur pipette and discarded. This experiment was repeated twice, with five replicate dishes per experiment.

\section{STATISTICAL ANALYSES}

Statistical analysis was performed using Minitab 12.1 (Minitab Inc., Coventry, Warwickshire, UK). When the data were not normally distributed they were arcsine or $\log _{10}$ transformed. Results of behavioural observations performed on exsheathed and ensheathed IJ on different dates were compared using a 2-way ANOVA. For comparisons between two test groups, Friedman's test was used.

\section{Results}

No differences $(P>0.05)$ in the seven behavioural categories due to storage time were found and nor was there any difference between exsheathed and ensheathed 


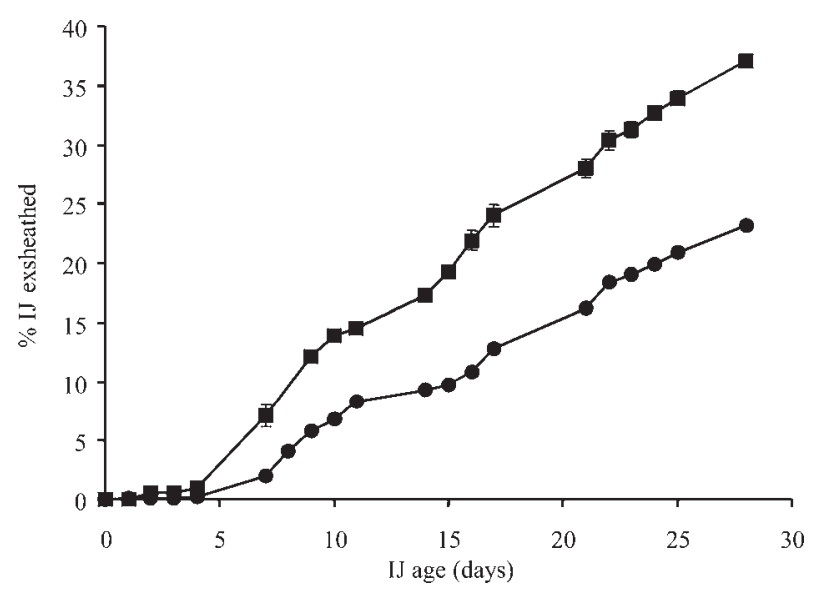

Fig. 1. The cumulative percentage of infective juveniles (IJ) of Heterorhabditis megidis exsheathing during storage in water at $20^{\circ} \mathrm{C}$. Each point represents the mean \pm SEM of $500 \mathrm{IJ}$ stored in bulk (ם) or 1200 IJ stored $(\mathbf{O})$.

IJ in the time spent in any of the behavioural categories. In both ensheathed and exsheathed IJ, immobility was the dominant behavioural category, occupying $60 \pm 5$ and $54 \pm 8 \%$ of the time, respectively. Body movement was the second most frequent behaviour, carried out for $23 \pm 3$ and $24 \pm 4 \%$ of the time in ensheathed and exsheathed IJ, respectively. Waving and headthrusting were of shorter duration, waving being displayed $6 \pm 2$ and $8 \pm 3 \%$ and head thrusting for $5 \pm 2$ and $8 \pm 3 \%$ in ensheathed and exsheathed IJ, respectively. Time spent in reverse wave, coiling and head lifting was never more than $2 \%$ of the observation time in either group of IJ.

Ensheathed IJ caused greater parasitism, killing on average $32 \pm 8.1 \%$ of the insects compared to $18 \pm 3.5 \%$ for exsheathed IJ $(P<0.05)$.

Exsheathment in individually and bulk stored IJ commenced on days 1 and 2 after harvest, respectively (Fig. 1). Less than $40 \%$ of the bulk stored IJ exsheathed during the 28 days of the experiment. Fewer of the individually stored IJ (23\%) exsheathed during the same period. In both treatments, nematode mortality was negligible (less than 6\%).

\section{Discussion}

Exsheathed $H$. megidis IJ were no less active than ensheathed, nor was the identity and duration of categories of behaviour expressed affected by the loss of the sheath. There were no significant differences in behaviour due to the age of the IJ over the period of 2-4 weeks after har- vest from the host. Changes in IJ behaviour were documented in $H$. megidis during the first 2 weeks post harvest (Dempsey \& Griffin, 2002) but, as in this study, no further significant change occurred in the next 2 weeks. The level of activity of $H$. megidis IJ was unaffected by the loss of the sheath in the present study: there was no difference between exsheathed and ensheathed IJ either in the time spent inactive or in the time spent waving, the normal mode of progression in nematodes (Croll, 1975). Motility of exsheathed and ensheathed $H$. bacteriophora IJ was not found to differ (Campbell \& Gaugler, 1992) but $S$. carpocapsae exsheathed IJ were significantly more motile (as measured by the proportion dispersing on agar) than ensheathed ones. Steinernematid sheaths adhere more loosely and may physically impede movement to a greater extent than in heterorhabditids. Exsheathment in steinernematids may be expected to increase freedom of movement or mobility more than in heterorhabditids (Campbell \& Gaugler, 1991b). Alternatively, as suggested by Campbell and Gaugler (1992), loss of the sheath in steinernematids may be a trigger for an increase in host finding.

Chemically desheathing IJ using sodium hypochlorite has been shown to alter the living cuticle (Davey \& Somerville, 1982; Timper \& Kaya, 1989) and may chemically activate the nematodes (Ishibashi \& Takii, 1993). Gross differences in behaviour of exsheathed and chemically desheathed IJ have been reported but the latter are not equivalent to naturally exsheathed IJ (Campbell \& Gaugler, 1991a, b, 1992; Ishibashi \& Takii, 1993). The barrier method (Campbell \& Gaugler, 1991a) may exclude less active exsheathed IJ and bias behavioural tests performed on IJ obtained by this method. Picking out individual IJ which have lost their sheath without experimental interference, as in the present study, is neither damaging nor selective and allows nematode behaviour to be examined and tested without compromising results.

Infectivity differed significantly between ensheathed and exsheathed IJ of $H$. megidis, with the infectivity of ensheathed IJ $14 \%$ greater than that of exsheathed IJ. This is the first demonstration of a difference in infectivity between ensheathed and exsheathed IJ for Heterorhabditis. Previous studies have reported that the presence of the sheath had no effect on the infectivity of $H$. bacteriophora or $S$. carpocapsae either on filter paper or in sand (Campbell \& Gaugler, 1991b, 1992; Ishibashi \& Takii, 1993). Ensheathed H. bacteriophora displayed greater infectivity than exsheathed when tested after 1 week at $100 \%$ relative humidity in sand (Campbell \& Gaugler, 
1991b). This effect was probably due to differential survival between sheathed and exsheathed nematodes. Moreover, exsheathed IJ used in that experiment had been selected by passage through a filter paper barrier. It is not clear whether ensheathed $H$. megidis are more infective because the sheath confers an advantage in survival and/or infection in the test arena, or because IJ exsheath when they have already undergone a decline in physiological parameters important for success in the assay.

To allow comparison with other investigations (Dempsey \& Griffin, 2002), IJ were stored in bulk as well as individually. Storage conditions had a considerable effect on the exsheathment rate. Less than a quarter of the individually stored $H$. megidis UK211 IJ had exsheathed after 4 weeks, at the conclusion of the experiment, when $40 \%$ of bulk stored IJ had exsheathed. Similar exsheathment rates were found in bulk stored $H$. megidis strain HF85 (Griffin \& Downes, 1990), though Jung (1991) reported a somewhat lower exsheathment rate in HF85 under the same conditions. Individually stored nematodes also displayed less active behaviour than bulk stored IJ: immobility was the dominant behaviour, comprising $60 \%$ of the observation time in the present investigation, compared to $24 \%$ for bulk stored IJ of the same age (Dempsey \& Griffin, 2002). Reasons for these differences in exsheathment rate and behaviour between bulk and individually stored IJ are unknown, but may be due to differences in osmotic stress (Croll, 1972; Womersley, 1990; Selvan et al., 1993; Davey, 1995), levels of excretory products (Lee \& Atkinson, 1976) or amount of mechanical stimulation (Ishibashi \& Kondo, 1990) in the two treatments.

\section{Acknowledgements}

Thanks to Micheal Keating, Trinity College, Dublin, Ireland for writing the programme for recording nematode behaviour and to Enterprise Ireland Strategic Research Programme for funding this work.

\section{References}

Bedding, R.A. \& Molyneux, A.S. (1982). Penetration of insect cuticle by infective juveniles of Heterorhabditis sp. (Heterorhabditidae:Nematoda). Nematologica 28, 354-359.

Campbell, J.F. \& Gaugler, R. (1991a). Mechanisms for exsheathment of entomopathogenic nematodes. International Journal for Parasitology 21, 219-224.
Campbell, J.F. \& Gaugler, R. (1991b). Role of the sheath in desiccation tolerance of two entomopathogenic nematodes. Nematologica 37, 324-332.

CAmpbell, J.F. \& Gaugler, R. (1992). Effect of exsheathment on motility and pathogenicity of two entomopathogenic nematode species. Journal of Nematology 24, 365-370.

Croll, N.A. (1972). Energy utilisation of infective Ancylostoma tubaeforme larvae. Parasitology 64, 355-368.

Croll, N.A. (1975). Behavioural analysis of nematode movement. Advances in Parasitology 13, 71-122.

DAVEY, K.G. (1995). Water, water compartments and water regulation in some nematodes parasitic in vertebrates. Journal of Nematology 27, 433-440.

DAVEY, K.G. \& Somerville, R.I. (1982). Changes in the optical path difference in the oesophageal region and the excretory cells during exsheathment in Haemonchus contortus. International Journal for Parasitology 12, 503-507.

DEMPSEY, C.M. \& GRIFFIN, C.T. (2002). Behavioural changes in Heterorhabditis megidis during storage. Parasitology 124 , 605-613.

GRIFFIN, C.T. (1996). Effects of prior storage conditions on the infectivity of Heterorhabditis sp. (Nematoda: Heterorhabditidae). Fundamental and Applied Nematology 19, 95-102.

Griffin, C.T. \& Downes, M.J. (1990). Exsheathment of Heterorhabditis sp. infective juveniles. Proceedings of the Vth International Colloquium on Invertebrate Pathology and Microbial Control. Adelaide, Australia, Society for Invertebrate Pathology, 234. [Abstr.]

IshibASHI, N. \& Kondo, E. (1990). Behaviour of infective juveniles. In: Gaugler, R. \& Kaya, H.R. (Eds). Entomopathogenic nematodes in biological control. Boca Raton, FL, USA, CRC Press, pp. 139-150.

ISHIBASHI, N. \& TAKII, S. (1993). Effects of insecticides on movement, nictation and infectivity of Steinernema carpocapsae. Journal of Nematology 25, 204-213.

JUNG, K. (1991). Observations on the infective juveniles of the insect parasitic nematode, Heterorhabditis sp., at two storage temperatures. Mededelingen van de Faculteit der Landbouwwetenschappen Rijksuniversiteit Gent 56/3B, 1305-1312.

KAYA, H.K. (1990). Entomopathogenic nematodes in biological control of insects. In: Baker, R. \& Dunn, P.E. (Eds). New directions in biological control: alternatives for suppressing agricultural pests and diseases. New York, USA, Alan R. Liss, pp. 189-198.

Lee, D.L. \& AtKinson, H.J. (1976). Physiology of nematodes. London, UK, Macmillan Press, pp. 112.

Matthews, B.E. (1972). Invasion of skin by the larvae of the cat hookworm, Ancylostoma tubaeforme. Parasitology65, 457-467.

O'Leary, S.A., Burnell, A.M. \& Kusel, J.R. (1998). Biophysical properties of the surface of desiccation-tolerantmutants and parental strain of the entomopathogenic nematode 
Heterorhabditis megidis (strain UK211). Parasitology 117, 337-345.

Patel, M.N. \& CAmpBell, W.C. (1997). Enhanced ability of third stage larvae of Haemonchus contortus to withstand drug exposure following chemically induced exsheathment. Journal of Parasitology 83, 971-973.

Peters, A. \& Ehlers, R.U. (1997). Encapsulation of the entomopathogenic nematode Steinernema feltiae in Tipula oleracea. Journal of Invertebrate Pathology 69, 218-222.

Rogers, W.P. \& Somerville, R.I. (1957). Physiology of exsheathment in nematodes and its relation to parasitism. Nature 179, 619-621.

Selvan, S., Campbell, J.F. \& Grewal, P. (1993). Water content and fatty acid composition of infective juvenile entomopathogenic nematodes during storage. Journal of Parasitology 79, 510-516.

TIMPER, P. \& KAYA, H.K. (1989). Role of the second stage cuticle of entomogenous nematodes in preventing infection by nematophagous fungi. Journal of Invertebrate Pathology 54, 314-321.

TIMPER, P. \& KAYA, H.K. (1992). Impact of a nematodeparasitic fungus on the effectiveness of entomopathogenic nematodes. Journal of Nematology 24, 1-8.

Wharton, D.A. \& Surrey, M.R. (1994). Cold tolerance of the infective larvae of the insect parasitic nematode Heterorhabditiszealandica Poinar. Cryo-Letters 15, 353-360.

Womersley, C.Z. (1990). Dehydration survival and anhydrobiotic potential. In: Gaugler, R. \& Kaya, H.R. (Eds). Entomopathogenic nematodes in biological control. Boca Raton, FL, USA, CRC Press, pp. 117-137.

WoOdring, J.L. \& KAYA, H.K. (1988). Steinernematid and heterorhabditid nematodes: a handbook of techniques. University of California, Davis, CA, USA, Southern Co-operative Series Bulletin 331, pp. 10-14. 